\title{
Deise Mancebo*
}

Universidade do Estado do Rio de Janeiro - UERJ - Rio de Janeiro, Rio de Janeiro, Brasil

\section{Adriana Benevides Soares**}

Universidade do Estado do Rio de Janeiro - UERJ - Rio de Janeiro, Rio de Janeiro, Brasil

\section{Alexandra Cleopatre Tsallis**}

Universidade do Estado do Rio de Janeiro - UERJ - Rio de Janeiro, Rio de Janeiro, Brasil

\section{Ana Maria Lopez Calvo de Feijoo**}

Universidade do Estado do Rio de Janeiro - UERJ - Rio de Janeiro, Rio de Janeiro, Brasil

\section{Deise Maria Leal Fernandes Mendes**}

Universidade do Estado do Rio de Janeiro - UERJ - Rio de Janeiro, Rio de Janeiro, Brasil

\section{Eleonôra Torres Prestrelo***}

Universidade do Estado do Rio de Janeiro - UERJ - Rio de Janeiro, Rio de Janeiro, Brasil

\section{Rita Maria Manso de Barros**}

Universidade do Estado do Rio de Janeiro - UERJ - Rio de Janeiro, Rio de Janeiro, Brasil

O encerramento de 2011 vem acompanhado de muitas promessas cumpridas e grandes expectativas para a Revista Estudos e Pesquisas em Psicologia.

Conseguimos honrar a decisão anteriormente tomada de aumentar nossa periodicidade para quadrimestral e publicar uma média de vinte trabalhos em cada edição. Além disso, nossa revista foi incluída em nova base de dados - Psicodoc -, bem como mantivemos nossa presença nas bases das quais já participávamos anteriormente. Tudo isso só foi possível devido à constância de nossa periodicidade, à agilidade da gestão do processo editorial e à qualidade dos artigos publicados. O trabalho de editores e funcionários da Revista viabilizou a infra-estrutura para essas conquistas, mas é preciso registrar as contribuições dos autores e consultores ad hocs, que fornecem a matéria prima central para que a qualidade da publicação seja assegurada. 
Os leitores perceberão que o resultado desse esforço coletivo traz uma amostra interessante das publicações em Psicologia e áreas afins que os convidamos a acompanhar.

Os três primeiros artigos que compõem esse número da Revista abordam questões do campo da saúde mental. O texto "A comunidade como espaço de produção de saúde mental", de Dayane Silva Rodrigues, Maria Aparecida Alves Sobreira de Carvalho e Verônica Morais Ximenes tem por discussão central a própria implantação da reforma psiquiátrica brasileira, assinalando as importantes conquistas que já foram obtidas com a proposição de serviços substitutivos ao manicômio. Contudo, adverte que a desinstitucionalização da loucura ultrapassa a esfera da desospitalização e se constitui, ainda, em um desafio. Em seguida, o texto "Esquizofrenia e criatividade artística" de Ana Cristina Resende e Irani Iracema de Lima Argimon constitui-se num estudo teórico sobre a problemática enunciada no título, baseado no levantamento da produção científica existente em importantes bases de dados nos últimos dez anos. Fechando esse primeiro bloco de textos, há o trabalho de Andréia Isabel Giacomozzi que, com o título "Representações sociais da droga e vulnerabilidade de usuários de CAPSad em relação às DST/HIV/AIDS", busca identificar as representações sociais do álcool e outras drogas, bem como as vulnerabilidades com relação às DST/HIV/Aids de usuários.

O próximo conjunto de artigos analisa, de diferentes perspectivas teóricas, a problemática do trabalho contemporâneo e suas mediações psicossociais. O texto "Análise das relações entre qualidade de vida e sobrecarga de cuidadoras de idosos", escrito por Carina Alexandra Rondini, J osé Sterza Justo, Fernando Silva Teixeira Filho, José Antonio Caruso de Lucca e Patrícia Aparecida de Oliveira procura traçar o perfil do cuidador informal de idosos da cidade de Assis, analisando as relações entre a qualidade de vida e índices de sobrecarga decorrentes dos afazeres de cuidado. O artigo seguinte, de Nair Monteiro da Silva e Helder Pordeus Muniz, leva o título "Vivências de trabalhadores em contexto de precarização". Nele, os autores expõem o cotidiano de trabalhadores do Setor de Emergências do Hospital Universitário Antonio Pedro, destacando as vivências subjetivas que podem ocorrer num contexto de trabalho precarizado. Em seguida, tem-se o artigo "Experiência em clínica do trabalho com profissionais de T\&D de uma organização pública", elaborado por Márcia Lucia Borges de Melo Gomes, Suzana Canez da Cruz Lima e Ana Magnólia Mendes, que relata uma experiência em clínica do trabalho com profissionais da área de treinamento e desenvolvimento de uma instituição do Poder Judiciário, baseada nos princípios da Psicodinâmica do Trabalho. 
Pode-se dizer que o próximo conjunto de textos transita na complexa interação do homem com sua cultura e sociedade. O primeiro é de Isabelle de Paiva Sanchis que, sob o título "Simmel e Goffman: uma comparação possível", problematiza a relação indivíduo/sociedade, tema caro à Psicologia Social, buscando categorias de mediação que ajudem a compreender a experiência dos sujeitos. Em seguida, temse o artigo "Apaixonados por carros como todo brasileiro", de Rebeca Carvalho de Morais, Jesus Garcia Pascual e Maria de Fátima Vieira Severiano, que sob uma matriz frankfurtiana, revisitam o conceito de indústria cultural, destacando sua atualidade para análise de fenômenos relacionados ao consumo e à publicidade, particularmente no que tange à constituição dos sujeitos. O próximo texto, de Jurema Barros Dantas, recebe o título "Um ensaio sobre o culto ao corpo na contemporaneidade", no qual a autora analisa o modo como a valorização do corpo vem se tornando um imperativo do viver contemporâneo. Outro trabalho que se reveste da maior relevância social é o de Anita Guazzelli Bernardes, Camilla Fernandes Marques e Laíza Piva Mázaro que abordam temática rara no campo de Psicologia: "A diferença tornada tradicional: formas de objetivação de populações indígenas", no qual a questão central indicada no título é problematizada a partir da análise das políticas públicas de saúde voltadas para essas populações, tendo por apoio teórico as ferramentas conceituais foucaultianas sobre verdade e política.

Finalizando os artigos apresentados em demanda espontânea, tivemos ainda "A produção da circulação de crianças", de Larissa Gonçalves Medeiros e Flávia Cristina Silveira Lemos, que realiza uma análise, a partir de estudos antropológicos, das naturalizações operadas em torno das idéias de infância e família, especialmente, aquelas operadas pela atuação de psicólogos e demais trabalhadores sociais. Em seguida, há o texto "Padrões de concordância entre múltiplos informantes na avaliação dos problemas comportamentais de adolescentes", de Marina Monzani da Rocha, Rafaela Almeida Ferrari e Edwiges Ferreira de Mattos Silvares, no qual as autoras buscam verificar padrões de concordância entre pais e adolescentes na avaliação dos problemas dos últimos e discutir as implicações clínicas das divergências. O próximo artigo é de Rafaela Tavares Nóbrega e Marineuza Monteiro da Silva Lucena, tem por título "Para além do transplante hepático: explorando a adesão ao tratamento", no qual as autoras buscam compreender o significado de adesão ao tratamento atribuído por transplantados hepáticos. O último artigo desse bloco leva o título "Resiliência e insucesso escolar", foi escrito por Francismara Neves de Oliveira e Lino de Macedo e apresenta uma reflexão sobre as salas de apoio à aprendizagem, sob a perspectiva de diferentes atores escolares. 
A seção CLIO, comparece neste número com dois artigos. O primeiro tem por título "Como se escreve, no Brasil, a História da Psicologia no contexto hospitalar?", no qual os autores - Denis Barros de Carvalho, Leylanne Martins Ribeiro de Souza, Lourena Silva Rosa e Máyra Laís de Carvalho Gomes - analisam a produção historiográfica brasileira sobre a inserção da Psicologia no contexto hospitalar à luz dos conceitos de História Crítica de Karl Danziger. O artigo seguinte é da autoria de José Augusto Evangelho Hernandez, intitula-se "João Carvalhaes, um psicólogo campeão do mundo de futebol" e nos fornece uma rara história das contribuições de J oão Carvalhaes para a Psicologia do Esporte no Brasil.

Há duas comunicações de pesquisa nesta edição: a de autoria de Renan Paiva Chaves, cuja pesquisa "Imagética musical" versa sobre os aspectos cognitivos da prática musical e a dos pesquisadores Carolina de Resende Damas Cardoso e Rodrigo Sanches Peres que apresentam a investigação "Estilos de enfrentamento religioso em mulheres acometidas por câncer de mama".

Por fim, encerrando a edição, são apresentadas duas resenhas: (1) a de Luciana Cristina Assini e Sílvio Paulo Botomé que analisam - com resenha que recebe o título "Abuso sexual infantil: esforços necessários para acabar com essa violência" - o livro "Prevenção do abuso sexual infantil" organizado por Lúcia Cavalcanti Albuquerque Williams e Eliane Aparecida Campanha Araújo, destacando o esforço interdisciplinar dos autores na abordagem do tema e (2) a de Luciana Loyola Madeira Soares que, com a resenha "A ética da reciprocidade: diálogo com Martin Buber", comenta a obra de mesmo nome, de autoria de Luiz José Veríssimo, registrando o rigor no uso da abordagem fenomenológica e existencial para o tratamento do tema.

Feita a apresentação, resta-nos desejar a todos uma boa leitura!

\section{Endereço para correspondência \\ Comissão Editorial}

Universidade do Estado do Rio de Janeiro - UERJ, Rua São Francisco Xavier, 524, Bloco F, $10^{\circ}$ andar, sala 10.005, Maracanã, CEP 20550-013, Rio de Janeiro-RJ, Brasil

Endereço eletrônico: revispsi@gmail.com

\section{Notas}

* Professora Titular do Instituto de Psicologia da Universidade do Estado do Rio de Janeiro - UERJ, Rio de Janeiro, RJ, Brasil.

** Professora Adjunta do Instituto de Psicologia da Universidade do Estado do Rio de Janeiro - UERJ, Rio de Janeiro, RJ, Brasil.

*** Professora Assistente do Instituto de Psicologia da Universidade do Estado do Rio de Janeiro- UERJ, Rio de Janeiro, RJ, Brasil. 